Check for updates

Cite this: Mater. Chem. Front., 2020, 4, 1404

Received 29th August 2019, Accepted 1st October 2019

DOI: $10.1039 / c 9 q m 00549 h$

rsc.li/frontiers-materials

\section{Zeolite-confined carbon dots: tuning thermally activated delayed fluorescence emission via energy transfer $\dagger$}

\author{
Hongyue Zhang, (D) ab Jiancong Liu, (D) ${ }^{c}$ Bolun Wang, ${ }^{a}$ Kaikai Liu, (D) ${ }^{a}$ \\ Guangrui Chen, ${ }^{a}$ Xiaowei Yu, ${ }^{a}$ Jiyang Li iD *a and Jihong Yu iD *ab
}

\begin{abstract}
Confining carbon dots (CDs) in zeolites may boost the thermally activated delayed fluorescence (TADF) emission. However, so far only blue-emissive CD-based TADF materials are reported, and rationally tuning the TADF emission of these materials remains challenging. Herein, by in situ embedding different emissive CDs into a zeolite matrix, we have successfully prepared a series of CD@zeolite composites with tunable TADF emission from blue to green by utilizing energy transfer (ET) between confined CDs. The as-prepared CDazeolite composites exhibit lifetimes varying from $271 \mathrm{~ms}$ to $860 \mathrm{~ms}$ and quantum yields ranging from $20 \%$ to $42 \%$. The ET process occurs from the singlet excited state of the blue emissive $C D$ donor to the singlet excited state of green emissive $C D$ acceptors with different polymerization degrees, promoting tunable TADF with cyan, mint green and olive green emission. The design concept proposed in this work may open a way to judicious tuning of the emission of TADF materials, and thus may broaden the applications of CD-based TADF materials.
\end{abstract}

\section{Introduction}

Thermally activated delayed fluorescence (TADF) materials have the ability to harvest triplet excitons and facilitate the reverse intersystem crossing $\left(\mathrm{T}_{1} \rightarrow \mathrm{S}_{1}\right)$ process, and have been inspiring intensive research for their potential applications in the optoelectronics, molecular imaging, and security fields. ${ }^{1-5}$ To date, the reported TADF materials are mainly based on metal organic complexes (e.g., $\mathrm{Cu}(\mathrm{I}), \mathrm{Ag}(\mathrm{I})$, and $\mathrm{Au}(\mathrm{I})$ complexes) $)^{6,7}$ and organic molecules (e.g., single-component organics, fullerenes and organic donor-acceptor molecules). ${ }^{8,9}$ Most of these materials have limited TADF lifetimes within microseconds to milliseconds, except one organic host-guest system was reported to possess the longest TADF lifetime over $1 \mathrm{~h}$ through photo-induced charge separation and recombination. ${ }^{4}$ However, the oxygen and temperature sensitivity, as well as complex fabrication processes, may restrict the practical application of these organic TADF materials. Therefore, it is highly desirable to develop environmentally stable, easy to synthesize and long-lasting TADF materials.

\footnotetext{
${ }^{a}$ State Key Laboratory of Inorganic Synthesis and Preparative Chemistry, College of Chemistry, Jilin University, Changchun 130012, P. R. China. E-mail: lijiyang@jlu.edu.cn, jihong@jlu.edu.cn

${ }^{b}$ International Center of Future Science, Jilin University, 2699 Qianjin Street, Changchun 130012, P. R. China

${ }^{c}$ Key Laboratory of Functional Inorganic Material Chemistry, Ministry of Education of the People's Republic of China, Heilongiiang University, Harbin 150080, China

$\dagger$ Electronic supplementary information (ESI) available. See DOI: 10.1039/c9qm00549h
}

In recent years, a new class of carbon dot (CD)-based afterglow materials have been prepared by embedding CDs into various matrices such as polyvinyl alcohol, ${ }^{10,11}$ potash alum, ${ }^{12}$ porous materials, ${ }^{13-15}$ and other matrices. ${ }^{16-19}$ In such composite materials, the host matrices can form hydrogen bonds with confined CDs, thus stabilizing the triplet states of CDs to achieve long-lifetime afterglow emission. Based on this design principle, several CD-based composites with room temperature phosphorescence (RTP) emission have been prepared. Compared with CD-based RTP materials, CD-based TADF materials usually show a shorter lifetime but higher quantum efficiency due to the reduction of thermal dissipation caused by nonradiative transitions during the long afterglow emission. However, so far CD-based TADF materials remain rarely reported. Our group developed a "dots-in-zeolite" strategy to prepare a series of blue emissive CD-based TADF materials with ultra-long lifetimes. ${ }^{14}$ In addition, we found that through varying the carbon precursors in the synthesis, the energy gap between $S_{1}$ and $\mathrm{T}_{1}$ of the CDs can be regulated, thus achieving the modulation of the TADF and RTP behaviors of the composites. ${ }^{20}$ However, the fabrication of CD-based composite materials with tunable TADF emission remains a challenge. Notice that energy transfer (ET) from the donor to the acceptor has been generally utilized to improve the energy storage capacity and lower the energy gap of the acceptor in constructing organic afterglow materials and metal organic TADF complexes. ${ }^{21-23}$ For instance, Yan's group reported a TADF-assisted ET route between two small organic molecules to 
prolong the RTP lifetime to $2 \mathrm{s.}^{24}$ More recently, our group prepared a red RTP CD-based composite based on ET between CDs and a Mn-doped zeolite matrix. ${ }^{25}$ Inspired by these studies, we hypothesize that the ET process might be also feasible between two kinds of CDs with matched energy levels in a zeolite matrix, thus affording the tuning of the photoluminescence properties.

Herein, we demonstrate an ET-assisted strategy to prepare CD-based TADF materials with tunable emission by confining different emitting CDs serving as donor-acceptor into a zeolite by a one-step hydrothermal synthesis. The as-made CD@zeolite composites exhibit tunable TADF emission colors from blue to green, variable lifetimes from $271 \mathrm{~ms}$ to $860 \mathrm{~ms}$ and quantum yields from $20 \%$ to $42 \%$. Such composites show potential applications in multicolour display and time-dependent security protection.

\section{Results and discussion}

\section{Synthesis and characterization of CD@MgAPO-5 composites}

The synthetic process of the CD@MgAPO-5 composite is illustrated in Scheme 1. Two different kinds of CD precursors were simultaneously carbonized into CDs and embedded into a zeolite matrix, giving CD-based composites with modulated TADF emission. The blue emissive TADF composite $\mathrm{CD}_{1} @ \mathrm{MgAPO}-5$ was synthesized by using 4,7,10-trioxa-1,13-tridecanediamine (TTDDA) as the template and carbon precursor of $\mathrm{CD}_{1}$ according to our previous work. ${ }^{14}$ Meanwhile, another kind of green emissive $\mathrm{CD}, \mathrm{CD}_{2}$, was synthesized by adding m-phenylenediamine (mPD) ${ }^{26}$ into the $\mathrm{CD}_{1} @ M g A P O-5$ composite. The composites were prepared in the hydrothermal reaction system of $\mathrm{Al}(\mathrm{OiPr})_{3}-\mathrm{MgHPO}_{4} \cdot 3 \mathrm{H}_{2} \mathrm{O}-$ $\mathrm{H}_{3} \mathrm{PO}_{4}-\mathrm{TTDDA}-x \mathrm{mPD}-\mathrm{H}_{2} \mathrm{O}$ at $180{ }^{\circ} \mathrm{C}$ for 3 days, during which TTDDA and MPD would carbonize into different kinds of CDs and were in situ confined into the zeolite matrix. By changing the initial molar ratio of $\mathrm{mPD}$ and TTDDA to $0,0.007,0.014$ and 0.042 , respectively, a series of CD-based composites named
CD 1 @MgAPO-5, CD $\mathrm{CD}_{2} @ M g A P O-5-\mathrm{a}, \quad \mathrm{CD}_{1} \mathrm{CD}_{2} @ M g A P O-5-\mathrm{b}$ and $\mathrm{CD}_{1} \mathrm{CD}_{2} @ \mathrm{MgAPO}-5$-c were prepared. The scanning electron microscopy (SEM) images of $\mathrm{CD}_{1} @ \mathrm{MgAPO}-5, \mathrm{CD}_{1} \mathrm{CD}_{2} @ \mathrm{MgAPO}-$ 5-a, $\mathrm{CD}_{1} \mathrm{CD}_{2} @ M g A P O-5-b$ and $\mathrm{CD}_{1} \mathrm{CD}_{2} @ M g A P O-5-c$ all display a similar polyhedral morphology (Fig. 1a, d and Fig. S1, ESI $\dagger$ ), and their powder X-ray diffraction (PXRD) patterns reveal that they all have the AFI zeolite framework structure (Fig. S2, ESI $\dagger$ ). The fluorescence microscopy images show that $\mathrm{CD}_{1} @ \mathrm{MgAPO}-5$ emits blue light, while $\mathrm{CD}_{1} \mathrm{CD}_{2} @ \mathrm{MgAPO}-5$-c emits green light under excitation with UV light (Fig. 1b and e). The transmission electron microscopy (TEM) images reveal that the CDs are all well-dispersed in the crystalline MgAPO-5 matrices (Fig. 1c, $\mathrm{f}$ and Fig. S3, ESI $\dagger$ ). The TEM images of the $\mathrm{CD}_{1} @ M g A P O-5$ and $\mathrm{CD}_{1} \mathrm{CD}_{2} @ M g A P O-5-c$ mother liquids show that the CDs have the same lattice spacing of $0.21 \mathrm{~nm}$ (Fig. 1c and $\mathrm{f}$ inset), but different average particle diameters, in which the CDs in $\mathrm{CD}_{1} @ \mathrm{MgAPO}-5$ $(3.33 \mathrm{~nm})$ have a larger diameter than that of $\mathrm{CD}_{1} \mathrm{CD}_{2} @ \mathrm{MgAPO}-5-\mathrm{c}$ $(2.57 \mathrm{~nm})$ (Fig. S4, ESI $\dagger$ ).

\section{Photoluminescence properties}

The as-synthesized composites show different photoluminescence behaviors. As shown in Fig. 2a, CD $@$ @MgAPO-5 shows blue emission at around $425 \mathrm{~nm}$ when excited by $360 \mathrm{~nm}$ UV light. For the series of $\mathrm{CD}_{1} \mathrm{CD}_{2} @ \mathrm{MgAPO}-5$ composites, with the increasing addition of $\mathrm{mPD}$, they present fluorescence emission varying from cyan and mint green to olive green (i.e., $\mathrm{CD}_{1} \mathrm{CD}_{2} @ M g A P O-5-\mathrm{a}: 484 \mathrm{~nm}$, CD $\mathrm{CD}_{2} @ M g A P O-5-b: 498$ nm, and $\mathrm{CD}_{1} \mathrm{CD}_{2} @ M g A P O-5-c: 515 \mathrm{~nm}$ ). The corresponding CIE coordinates of these CD-based composites vary from $(0.17,0.12)$ to $(0.29,0.48)$ (Fig. S5, ESI $\dagger$ ).

Remarkably, these CD-based composites all show longlifetime photoluminescence when the excitation source is turned off (Fig. 2b and f). The emission bands of the delayed fluorescence (Fig. 2e) are almost consistent with those of the prompt fluorescence (Fig. 2a). In detail, the emission bands of the

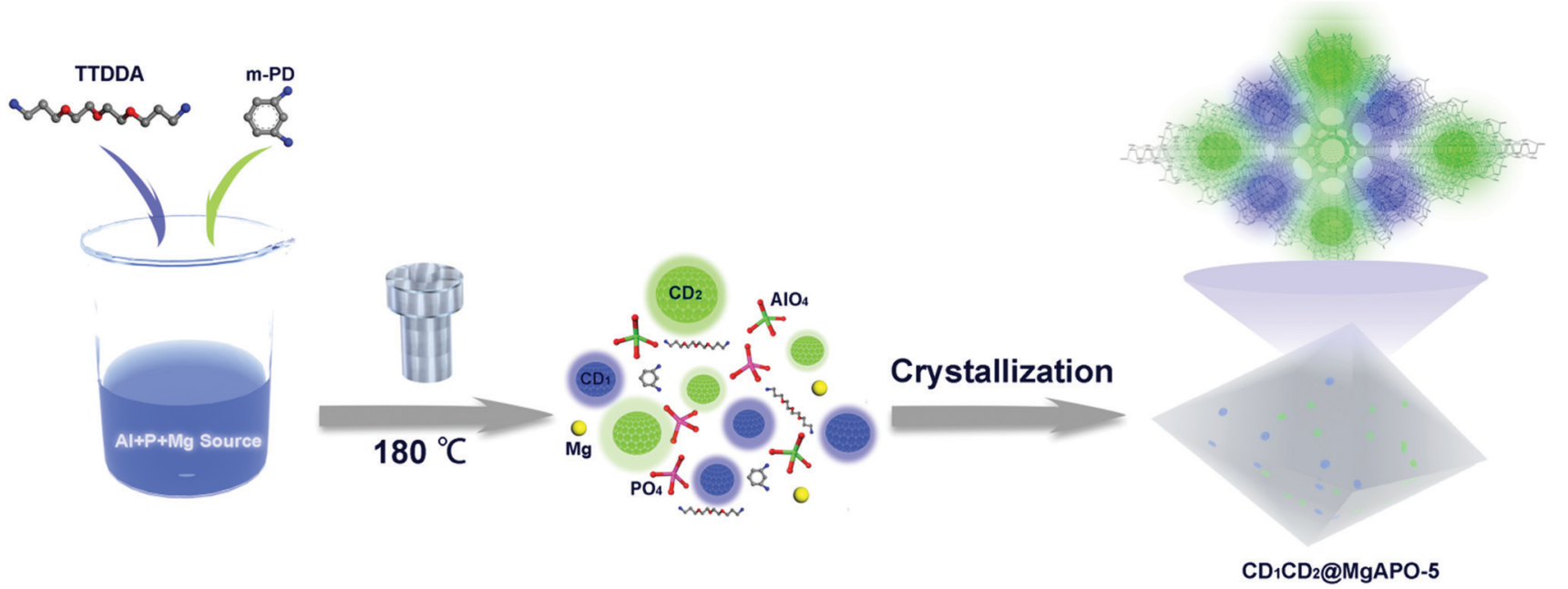

Scheme 1 Formation process of the $\mathrm{CD}_{1} \mathrm{CD}_{2} @ \mathrm{aMgAPO}-5$ composites. The reaction mixture is composed of an $\mathrm{Al}$ source, $\mathrm{P}$ source and $\mathrm{Mg}$ source for synthetic MgAPO-5; TTDDA acted as a template as well as the precursor of $C_{1}$, and mPD as the precursor of $C_{2}$. Under hydrothermal conditions, TTDDA and $\mathrm{mPD}$ are carbonized into blue emissive $C D_{1}$ and green emissive $C D_{2}$, respectively; meanwhile, the MgAPO-5 zeolite framework is crystallized. As a result, the two kinds of CDs are in situ embedded inside the zeolite matrix. 

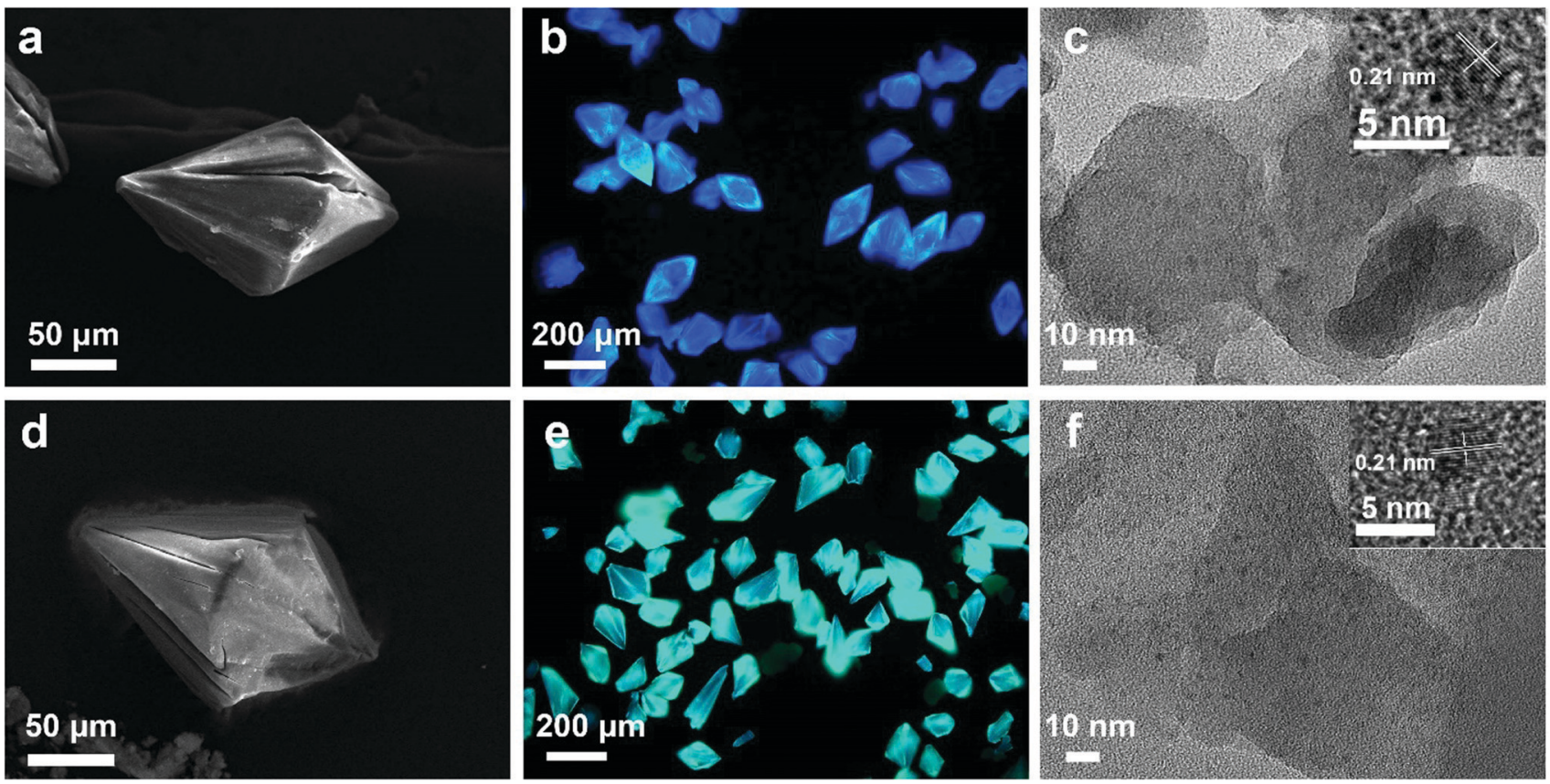

Fig. 1 (a and d) SEM images of the $C_{1}\left(\mathrm{aMgAPO}-5\right.$ and $\mathrm{CD}_{1} \mathrm{CD}_{2}(\mathrm{aMgAPO}-5-\mathrm{c}$ composites, respectively. (b and e) Fluorescence microscopy images of

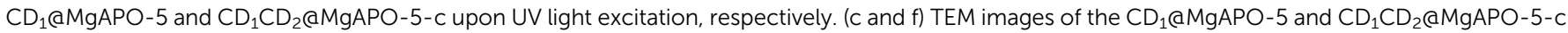
composites, respectively (inset, HRTEM images of CDs from the mother liquid with a lattice spacing of $0.21 \mathrm{~nm}$ )
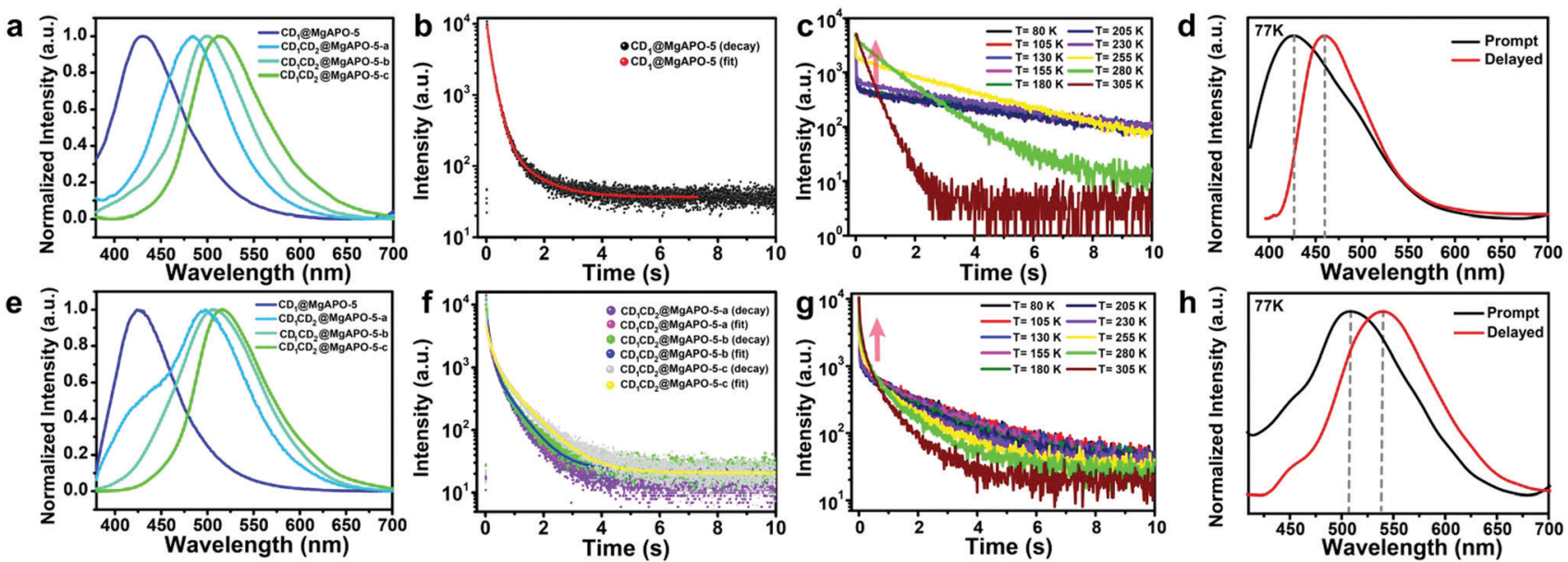

Fig. 2 Photoluminescence (PL) spectra of the CD-based composites. (a) The normalized steady-state PL spectra of the CD-based composites excited by $360 \mathrm{~nm}$ UV light. (b) The time-resolved decay spectra of $\mathrm{CD}_{1} @ \mathrm{QMgAPO}-5$ at room temperature. (c) Temperature-dependent time-resolved decay spectra of $C_{1}$ (aMgAPO- 5 monitored at $425 \mathrm{~nm}$ emission. (d) The normalized steady-state (black line) and delayed (red line) PL spectra of $C D_{1} @ M g A P O-$ 5 excited by $\lambda=360 \mathrm{~nm}$ at $77 \mathrm{~K}$. (e) The normalized delayed PL spectra of the CD-based composites at room temperature and in an ambient atmosphere. (f) The time-resolved decay spectra of the CD-based composites at room temperature. (g) Temperature-dependent time-resolved decay spectra of $\mathrm{CD}_{1} \mathrm{CD}_{2} \mathrm{QMgAPO}-5-\mathrm{c}$ monitored at $515 \mathrm{~nm}$ emission. (h) The normalized steady-state (black line) and delayed (red line) photoluminescence spectra of $\mathrm{CD}_{1} \mathrm{CD}_{2}(\mathrm{QMgAPO}-5-\mathrm{c}$ excited by $\lambda=360 \mathrm{~nm}$ at $77 \mathrm{~K}$.

delayed fluorescence are centered at $425 \mathrm{~nm}$ for $\mathrm{CD}_{1} @ \mathrm{MgAPO}-5$, $497 \mathrm{~nm}$ for $\mathrm{CD}_{1} \mathrm{CD}_{2} @ \mathrm{MgAPO}-5-\mathrm{a}, 505 \mathrm{~nm}$ for $\mathrm{CD}_{1} \mathrm{CD}_{2} @ \mathrm{MgAPO}-$ 5-b and $515 \mathrm{~nm}$ for $\mathrm{CD}_{1} \mathrm{CD}_{2} @ M g A P O-5-c$. According to the previous report, the $\mathrm{CD}_{1} @ \mathrm{MgAPO}-5$ composite is a typical TADF material. ${ }^{14}$ In order to investigate the species of delayed fluorescence in the composites after adding $\mathrm{CD}_{2}$, the lifetime of delayed fluorescence at $515 \mathrm{~nm}$ for the $\mathrm{CD}_{1} \mathrm{CD}_{2} @ \mathrm{MgAPO}-5-\mathrm{c}$ composite was monitored when the temperature was increased from $80 \mathrm{~K}$ to $305 \mathrm{~K}$ (Fig. $2 \mathrm{~g}$ ). As the temperature rises, the longlifetime components increase (Table S1, ESI $\dagger$ ), being similar to that of the $\mathrm{CD}_{1} @ \mathrm{MgAPO}-5$ composite (Fig. 2c and Table S2, ESI $\dagger$ ), which is characteristic of thermally activated delayed fluorescence. ${ }^{27,28}$ In addition, $\mathrm{CD}_{1} \mathrm{CD}_{2} @ \mathrm{MgAPO}-5$-a and $\mathrm{CD}_{1} \mathrm{CD}_{2}$ @ MgAPO-5-b also show similar phenomena of increased longlifetime components with increased temperature (Fig. S6, ESI $\dagger$ ). Considering a slight red shift in the delayed spectra compared 
with the prompt spectra of $\mathrm{CD}_{1} \mathrm{CD}_{2} @ M g A P O-5-\mathrm{a}$ and $\mathrm{CD}_{1} \mathrm{CD}_{2} @$ MgAPO-5-b, we could not exclude the co-existence of a minor component of phosphorescence emission with the TADF emission because of the broad emission peak of the delayed spectra. Therefore, we suppose that these $\mathrm{CD}_{1} \mathrm{CD}_{2} @ \mathrm{MgAPO}-5$ composite materials should be categorized as TADF materials. Furthermore, the energy gap $\left(\Delta E_{\mathrm{ST}}\right)$ between the excited singlet state $\left(\mathrm{S}_{1}\right)$ and the excited triplet state $\left(\mathrm{T}_{1}\right)$ is also an important criterion for TADF materials. The $\mathrm{S}_{1}$ and $\mathrm{T}_{1}$ energy levels of $\mathrm{CD}_{1} \mathrm{CD}_{2} @ \mathrm{MgAPO}-5$-c are determined using the prompt and delayed spectra at $77 \mathrm{~K} . \Delta E_{\mathrm{ST}}$ of $\mathrm{CD}_{1} \mathrm{CD}_{2} @ M g A P O-5-c$ is $0.14 \mathrm{eV}$, which is lower than that of $\mathrm{CD}_{1} @$ MgAPO-5 $(0.20 \mathrm{eV})$ (Fig. $2 \mathrm{~h}$ and d). This suggests that the $\mathrm{CD}_{1} \mathrm{CD}_{2} @ \mathrm{MgAPO}-5-\mathrm{c}$ composite has a small energy gap for facilitating the electron flow through intersystem crossing (ISC) and reverse intersystem crossing (RISC) between $S_{1}$ and $T_{1}$ to achieve the TADF phenomenon. ${ }^{29,30}$ Moreover, through varying the addition amount of $\mathrm{MPD}$, the quantum yields and TADF lifetimes of the composites can be modulated from $20 \%$ to $42 \%$, and $271 \mathrm{~ms}$ to $860 \mathrm{~ms}$ at $\lambda_{\mathrm{ex}}=360 \mathrm{~nm}$, respectively (Tables S3 and S4, ESI $\dagger$ ).

To gain insight into the photoluminescence mechanism of these CD-based composites, the structures of the CDs in the composites were studied. The mother liquid of $\mathrm{CD}_{1} \mathrm{CD}_{2} @ \mathrm{MgAPO}-$ 5-c was separated by thin layer silica chromatography. Unexpectedly, several components of the CDs with multi-emissive properties were obtained, named $\mathrm{CD}_{1}\left(\lambda_{\mathrm{em}}=435 \mathrm{~nm}\right), \mathrm{CD}_{2}$-a $\left(\lambda_{\mathrm{em}}=487 \mathrm{~nm}\right), \mathrm{CD}_{2}$-b $\left(\lambda_{\mathrm{em}}=503 \mathrm{~nm}\right)$ and $\mathrm{CD}_{2}-\mathrm{c}\left(\lambda_{\mathrm{em}}=515 \mathrm{~nm}\right)$ (Fig. S7, ESI $\left.\dagger\right)$. According to the previous reports, $\mathrm{CD}_{1}$ originates from the precursor of TTDDA, while $\mathrm{CD}_{2}$ with three components originates from organic amine mPD. X-ray photoelectron spectroscopy (XPS) spectra show that the three kinds of $\mathrm{CD}_{2}$ all have more pyrrolic $\mathrm{N}$ and pyridinic $\mathrm{N}$, but a little amino $\mathrm{N}$ compared with $\mathrm{CD}_{1}$ (Fig. S8, ESI $\dagger$ ). Specifically, the $\mathrm{C}-\mathrm{N}$ and $\mathrm{C}=\mathrm{O} / \mathrm{C}=\mathrm{N}$ components increase and the $\mathrm{C}-\mathrm{O}$ component decreases from $\mathrm{CD}_{2}$-a to $\mathrm{CD}_{2}$-c. It may be caused by the different polymerization degrees resulting from different amounts of the added MPD in the synthesis, which gives different functional groups on the resulting $\mathrm{CD}_{2}$. The different surface groups of $\mathrm{CD}_{2}$-a to $\mathrm{CD}_{2}$-c lead to the distinct fluorescence emission. Note that the fluorescence spectra of $\mathrm{CD}_{2}-\mathrm{a}, \mathrm{CD}_{2}-\mathrm{b}$ and $\mathrm{CD}_{2}-\mathrm{c}$ are almost consistent with those of the $\mathrm{CD}_{1} \mathrm{CD}_{2} @ M g A P O-5-\mathrm{a}$, $\mathrm{CD}_{1} \mathrm{CD}_{2} @ M g A P O-5-b$ and $\mathrm{CD}_{1} \mathrm{CD}_{2} @ M g A P O-5-c$ composites, respectively, suggesting $\mathrm{CD}_{2}$-a, $\mathrm{CD}_{2}$-b and $\mathrm{CD}_{2}$-c are the respective dominant $\mathrm{CD}_{2}$ components in the corresponding composites, although they may co-exist. The XPS results of the composites show that the $\mathrm{C}-\mathrm{N}$ (especially for pyrrolic $\mathrm{N}$ and pyridinic $\mathrm{N}$ ) and $\mathrm{C}=\mathrm{O} / \mathrm{C}=\mathrm{N}$ components increase and the $\mathrm{C}-\mathrm{O}$ component decreases from $\mathrm{CD}_{1} \mathrm{CD}_{2} @ M g A P O-5-a$ to $\mathrm{CD}_{1} \mathrm{CD}_{2} @ \mathrm{MgAPO}-5-\mathrm{c}$, being consistent with the above XPS analysis results of separated $\mathrm{CD}_{2}-\mathrm{a}, \mathrm{CD}_{2}$-b and $\mathrm{CD}_{2}$-c (Fig. S9, ESI $\dagger$ ).

The unique confinement effect of the zeolite matrix was further confirmed by the spectra of $\mathrm{CD}$ solutions. By taking $\mathrm{CD}_{1}$ and $\mathrm{CD}_{2}$-c as examples, Fig. S10 (ESI $\dagger$ ) shows their emission spectra under the excitation of $360 \mathrm{~nm}$ UV light. When changing the excitation wavelength from $320 \mathrm{~nm}$ to $480 \mathrm{~nm}, \mathrm{CD}_{1}$ emits excitation-dependent luminescence varying from 400 to $500 \mathrm{~nm}$, with the strongest emission centered at around $435 \mathrm{~nm}$ (excited at $360 \mathrm{~nm}$ ), while $\mathrm{CD}_{2}$-c emits excitation-independent luminescence centered at around $515 \mathrm{~nm}$ and the strongest emission is achieved upon excitation at $460 \mathrm{~nm}$. The lifetimes of $\mathrm{CD}_{1}$ and $\mathrm{CD}_{2}$ aqueous solution are $6.68 \mathrm{~ns}$ and $9.45 \mathrm{~ns}$, respectively (Fig. S11 and Table S5, ESI $\dagger$ ). Long-lifetime emission was not observed for both $\mathrm{CD}_{1}$ and $\mathrm{CD}_{2}-\mathrm{c}$ when the UV light was turned off. This phenomenon implies that the zeolitic matrix can effectively stabilize the triplet excited state of the CDs and restrict the non-radiation dissipated by rotation and vibration to realize long-lifetime emission. The $\mathrm{CD}_{1} \mathrm{CD}_{2} @ \mathrm{MgAPO}-5$-c composite also shows strong photoluminescence (PL) stability under UV radiation or in air. When being irradiated under UV light or ground in air for 8 hours, it retains a PL intensity of $80 \%$ (Fig. S12, ESI $\dagger$ ). Moreover, the CD@MgAlPO-5 composites are not sensitive to oxygen, and their TADF lifetimes are similar under air and $\mathrm{N}_{2}$ conditions (Fig. S13, ESI $\dagger$ ). This high photo-stability and airstability of the $\mathrm{CD}_{1} \mathrm{CD}_{2} @ \mathrm{MgAPO}-5$-c composite are superior to most organic TADF materials, ${ }^{31-33}$ which may benefit from the stabilization effect of the zeolite matrix.

\section{Energy transfer process}

Comparing the fluorescence spectra and the delayed fluorescence spectra of these four composites, we found that with the increasing addition of $\mathrm{mPD}$ in the synthesis, the blue emission from $\mathrm{CD}_{1}$ becomes weak and almost vanishes in the $\mathrm{CD}_{1} \mathrm{CD}_{2} @ \mathrm{MgAPO}-5$-c composite (Fig. S14, ESI $\dagger$ ). Considering the existence of multiple CD species in the composites, we suppose that there may exist an energy transfer (ET) process between $\mathrm{CD}_{1}$ (from template TTDDA) and $\mathrm{CD}_{2}$ (from introduced $\mathrm{mPD}$ ) in these composites. The absorption bands of the three types of $\mathrm{CD}_{2}$ all have large spectral overlap integrals with the emission band of $\mathrm{CD}_{1}$ at 400-470 nm (Fig. 3a), suggesting that ET may occur between the donor $\mathrm{CD}_{1}$ and the acceptor $\mathrm{CD}_{2}$ with three different components. The increasing overlap indicates a more efficient ET process from $\mathrm{CD}_{1} \mathrm{CD}_{2} @ \mathrm{MgAPO}-5-\mathrm{a}$ to $\mathrm{CD}_{1} \mathrm{CD}_{2} @ \mathrm{MgAPO}-5-\mathrm{c}$. Moreover, the zeolite matrix provides a suitable space that makes the $\mathrm{D}\left(\mathrm{CD}_{1}\right)-\mathrm{A}\left(\mathrm{CD}_{2}\right)$ pairs near enough to achieve the ET process according to Dexter's theory of energy transfer. ${ }^{34-36}$

Furthermore, the prompt fluorescence lifetimes of these CD-based composites were also detected (Fig. 3b). Compared with $\mathrm{CD}_{1} @ \mathrm{MgAPO}-5$, the lifetime values of the emission band at $425 \mathrm{~nm}$ for $\mathrm{CD}_{1} \mathrm{CD}_{2} @ \mathrm{MgAPO}-5-\mathrm{a}, \mathrm{CD}_{1} \mathrm{CD}_{2} @ \mathrm{MgAPO}-5-\mathrm{b}$ and $\mathrm{CD}_{1} \mathrm{CD}_{2} @ \mathrm{MgAPO}-5-\mathrm{c}$ decrease greatly at $\lambda_{\mathrm{ex}}=360 \mathrm{~nm}$, which indicates that the effective ET originated from the singlet states of $\mathrm{CD}_{1}$ and $\mathrm{CD}_{2}$. Thus, the possible ET mechanism for these composites is proposed as follows: $\mathrm{CD}_{2}$ acceptors with different emission and energy levels were produced when different amounts of $\mathrm{mPD}$ were added in the synthesis. $\mathrm{CD}_{2}$ could efficiently harvest singlet excitons of the donor $\mathrm{CD}_{1}$, while the stabilized triplet states and small energy gap $\left(\Delta E_{\mathrm{ST}}\right)$ of $\mathrm{CD}_{2}$ make possible ISC and RISC between the $\mathrm{S}_{1}$ and $\mathrm{T}_{1}$ states, leading to enhanced TADF emission in $\mathrm{CD}_{2}$ (Fig. $4 \mathrm{a}$ ). In addition, the photoluminescence spectrum of $\mathrm{CD}_{1} \mathrm{CD}_{2} @ \mathrm{MgAPO}-5-\mathrm{c}$ at $77 \mathrm{~K}$ shows an additional blue emission peak located around $450 \mathrm{~nm}$, which is quite weak at room temperature (Fig. 3c). This indicates that the ET process between different CDs is suppressed at low temperature, which is a typical feature for energy transfer. ${ }^{37,38}$ 

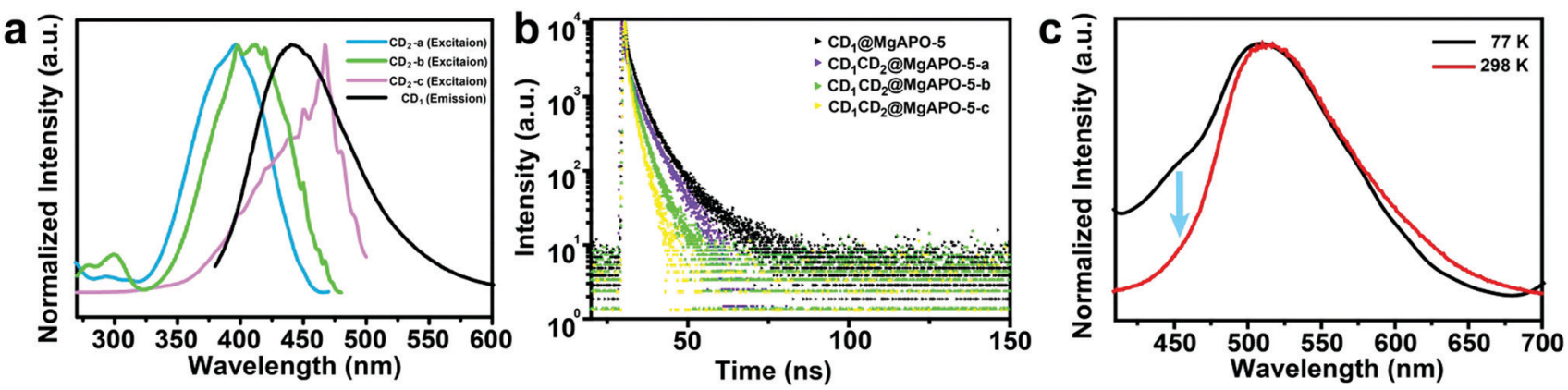

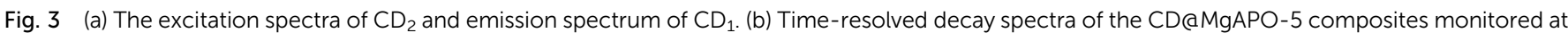
$\lambda_{\mathrm{em}}=425 \mathrm{~nm}$. (c) The photoluminescence spectra of the $\mathrm{CD}_{1} \mathrm{CD}_{2}$ @MgAPO-5-c composite measured at $298 \mathrm{~K}$ (red line) and $77 \mathrm{~K}$ (black line).

The ET efficiency of these CD-based composites can be quantified according to the equation $\eta=1-\tau_{\mathrm{DA}} / \tau_{\mathrm{D}}$, in which $\tau_{\mathrm{DA}}$ and $\tau_{\mathrm{D}}$ represent the PL lifetimes of the energy donor in the presence and absence of the energy acceptor, respectively. ${ }^{39-42}$ Based on this, the ET efficiencies from $\mathrm{CD}_{1} \mathrm{CD}_{2}$ @MgAPO-5-a to $\mathrm{CD}_{1} \mathrm{CD}_{2}$ @MgAPO-5-c are calculated as 43.72\%, 53.10\% and $73.0 \%$, respectively. This result manifests that the ET efficiency increases through enhancing the polymerization degree of the introduced $\mathrm{CD}_{2}$ in the zeolite matrix, which is consistent with the above-mentioned increasing overlap between the absorption peaks of $\mathrm{CD}_{2}$ and emission peak of $\mathrm{CD}_{1}$ from $\mathrm{CD}_{1} \mathrm{CD}_{2}$ @MgAPO-5-a to $\mathrm{CD}_{1} \mathrm{CD}_{2}$ @MgAPO-5-c (Fig. 3a). The high ET efficiency may facilitate the increasing TADF lifetimes and QYs of these composites. It should be pointed out that although our previous work has demonstrated ET between CDs and a Mn-doped zeolite matrix, ${ }^{25}$ ET between different types of CDs in a matrix is presented for the first time in this CD-based system.

\section{Application: multicolour display and time-dependent security protection}

On the basis of the modulated TADF lifetimes and emission colors of the as-synthesized CD-based composites, we demonstrate their potential applications in multicolour display and time-dependent security protection. An encryption algorithm was designed with three modes of operation: "UV on", "UV off (instantly)", and "UV off (for $1 \mathrm{~s}$ and $3 \mathrm{~s}$ )". As shown in Fig. 4b, the pattern "idea" with a size of $4 \mathrm{~cm}$ was fabricated with the above-mentioned four kinds of CD-based composites $\left(\mathrm{CD}_{1}\right.$ @ MgAPO-5, CD $C_{1} \mathrm{DD}_{2} @ M g A P O-5-\mathrm{a}, \mathrm{CD}_{1} \mathrm{CD}_{2} @ M g A P O-5-\mathrm{b}$ and $\left.\mathrm{CD}_{1} \mathrm{CD}_{2} @ M g A P O-5-c\right)$. Under excitation with 365 nm UV light, the four letters "i", “d”, "e" and "a" are blue, cyan, mint green and olive green, respectively. When switching off the excitation source, these four letters all can be seen by the naked eye and their TADF colors are similar to their fluorescence emission under UV on. As time extends, these four letters fade away gradually due to different TADF lifetimes. In detail, after

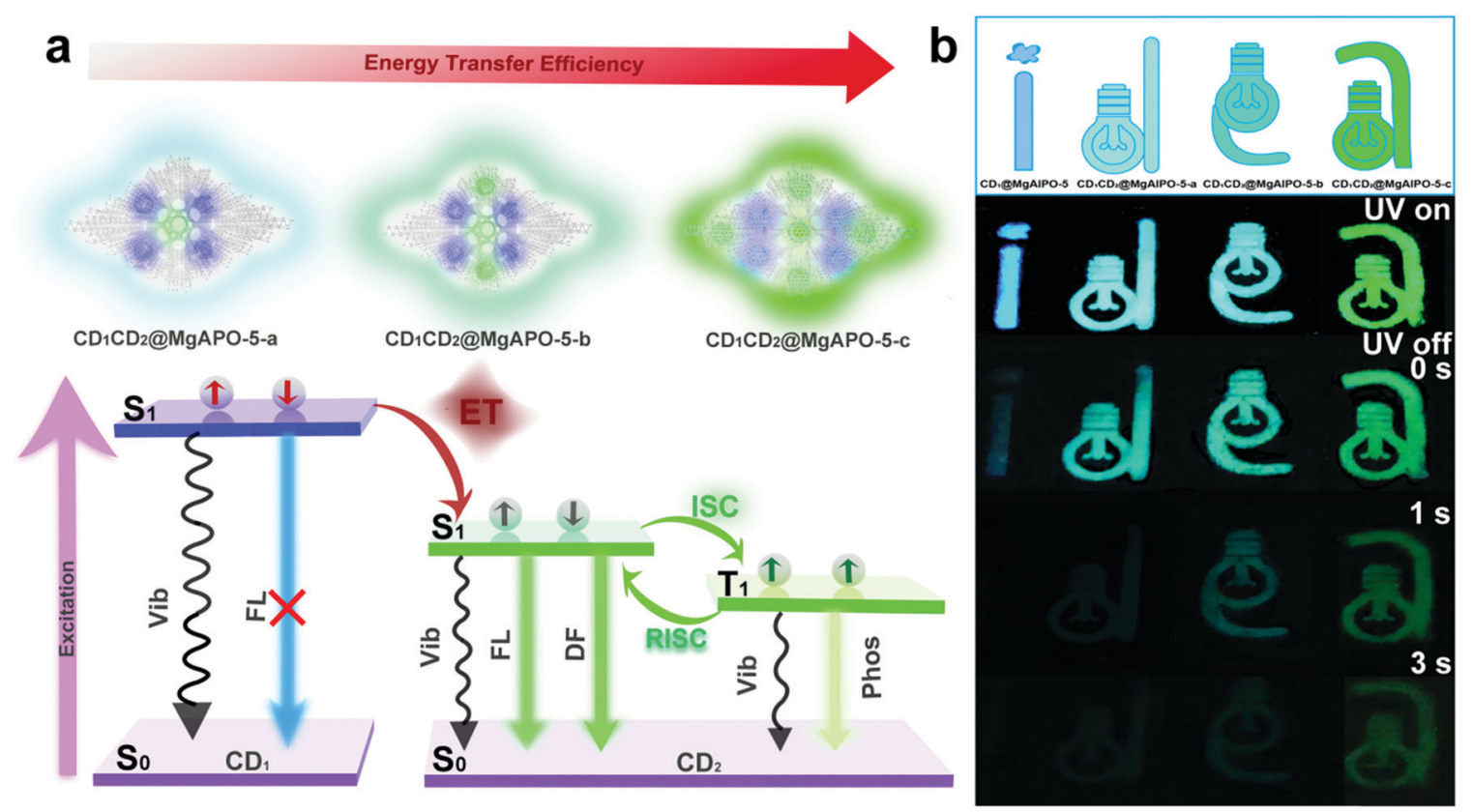

Fig. 4 (a) Proposed ET mechanism of different CDs in the composite. (b) Multicolour display and time-dependent security protection of the CD-based composites. 
turning off the UV light for $1 \mathrm{~s}$, the letters " $\mathrm{i}$ " and " $\mathrm{d}$ " are invisible, and gradually, extending to $3 \mathrm{~s}$, only the letter " $\mathrm{e}$ " can be captured. Besides the application in security protection, it is believed that the CD@zeolite composites with long-lived TADF can serve as ideal contrast agents for future high-sensitivity bioimaging to efficiently avoid short-lived background fluorescence.

\section{Conclusion}

A series of CD@zeolite TADF materials with modulated emission colors, lifetimes and QYs have been successfully prepared by embedding different kinds of CDs into a zeolite matrix via in situ hydrothermal synthesis. $\mathrm{CD}_{1}$ with blue emission has a relative high energy level, while $\mathrm{CD}_{2}$ composed of three components with emission from cyan to green has relatively low energy levels; their co-existence in the nanospace of the zeolite matrix enables energy transfer between them. The energy transfer efficiency increases with the enhanced polymerization degree of $\mathrm{CD}_{2}$ in the composite. By varying the composition of the CDs, four kinds of CD-based composites are achieved with multicolour emission from blue, cyan, and mint green to olive green, TADF lifetimes from $271 \mathrm{~ms}$, $578 \mathrm{~ms}$, and $801 \mathrm{~ms}$ to $860 \mathrm{~ms}$, and QYs from 20\%, 25\%, and 37\% to $42 \%$. Based on the unique TADF properties, these CD-based composites can be potentially used in multicolour display and time-dependent security protection. This work provides a feasible strategy to modulate the afterglow emission of CD-based composites in terms of the ET route, which will be helpful for the design and fabrication of novel CD-based composites with desired photoluminescence properties.

\section{Experimental}

\section{Materials}

All reagents were used as received without purification. Aluminum isopropoxide ( $98 \%$ purity) and TTDDA (97\% purity) were purchased from Sigma-Aldrich. $\mathrm{MgHPO}_{4} \cdot 3 \mathrm{H}_{2} \mathrm{O}$ and $\mathrm{H}_{3} \mathrm{PO}_{4}$ (85 weight\% (wt\%) in water) were obtained from Tianjin Fuchen Chemical Co. Ltd. $M$-Phenylenediamine was supplied by Beijing Chemical Reagent Factory. Deionized (DI) water was obtained from Milli-Q purification equipment.

\section{Instruments}

Powder X-ray diffraction (PXRD) data were measured with a RigakuD/Max 2500 diffractometer with $\mathrm{Cu} \mathrm{K} \alpha$ radiation $(\lambda=$ $1.5418 \AA$ A). The transmission electron microscopy (TEM) images were taken on a Tecnai F20 electron microscope. Scanning electron microscopy (SEM) images were taken on a JSM-6510 (JEOL) electron microscope. Fluorescence microscopy images were taken by using an Olympus BX51 microscope under UV excitation. The XPS measurements were collected on a ThermoESCALAB250 spectrometer with monochromatized $\mathrm{Al} \mathrm{K} \alpha$ excitation.

\section{Synthesis of the CD-based composites}

The series of CD-based composites were synthesized by using TTDDA as the SDA under hydrothermal conditions. In the synthesis of $\mathrm{CD}_{1} @ \mathrm{MgAPO}-5$, aluminum isopropoxide was dispersed in $\mathrm{H}_{3} \mathrm{PO}_{4}$ aqueous solution. Then, $\mathrm{MgHPO}_{4} \cdot 3 \mathrm{H}_{2} \mathrm{O}$ and TTDDA were added into the mixture with stirring. A homogeneous gel was formed with a molar composition of $1.0 \mathrm{Al}_{2} \mathrm{O}_{3}$ : $0.1 \mathrm{MgO}: 2.0 \mathrm{P}_{2} \mathrm{O}_{5}: 2.1 \mathrm{TTDDA}: 139 \mathrm{H}_{2} \mathrm{O}$. After crystallization at $180{ }^{\circ} \mathrm{C}$ for 3 days, the crystalline product was washed with distilled water, and dried at $80{ }^{\circ} \mathrm{C}$ in an oven. Similarly, $\mathrm{CD}_{1} \mathrm{CD}_{2} @ \mathrm{MgAPO}-5$ composites were synthesized by adding $\mathrm{m}$-PD into the abovementioned homogeneous gel with stirring. Through changing the molar ratio of $\mathrm{mPD}$ and TTDDA in the reaction gel to $0.007,0.014$ and 0.042 , respectively, a series of $\mathrm{CD}_{1} \mathrm{CD}_{2} @ \mathrm{MgAPO}-5$ composites were produced, which were named $\mathrm{CD}_{1} \mathrm{CD}_{2} @ \mathrm{MgAPO}-5-\mathrm{a}$, $\mathrm{CD}_{1} \mathrm{CD}_{2} @ M g A P O-5-b$, and $\mathrm{CD}_{1} \mathrm{CD}_{2} @ M g A P O-5-c$. The subsequent steps were the same as the above mentioned for the synthesis of $\mathrm{CD}_{1} @ \mathrm{MgAPO}-5$.

\section{Photoluminescence measurements of the CD-based composites}

Steady-state and delayed spectra were measured on a HORIBA Scientific FluoroMax-4 spectrofluorometer. The fluorescence lifetime spectra were measured using a FluoroHub-B fluorescence lifetime system equipped with a photomultiplier tube detector in a HORIBA Scientific FluoroMax-4. Ludox was selected to rectify the instrument response factor (IRF). The lifetime data were fitted by using DAS6 software with a multi-exponential model. The average lifetimes $\left(\tau_{\text {avg }}\right)$ are shown as $\tau_{\text {avg }}=\Sigma A_{\mathrm{i}} \tau_{\mathrm{i}}^{2} / \Sigma A_{\mathrm{i}} \tau_{\mathrm{i}}$, in which $A_{\mathrm{i}}$ is the preexponential for lifetime $\tau_{\mathrm{i}}$. Temperature-dependent transient photoluminescence decay was collected on an Edinburgh FLS920 fluorescence spectrophotometer. The fluorescence QY was collected on an Edinburgh FLS920 with an integrating sphere. To prove the accuracy of the as-measured QY, sodium salicylate solid was used as a reference. The measured QY (52.33\%) was close to its standard QY of $52.0 \%$.

\section{Conflicts of interest}

There are no conflicts to declare.

\section{Acknowledgements}

The authors are thankful for financial support from the National Natural Science Foundation of China (Grant No. 21835002, 21621001 and 21671075), and the 111 Project of China (B17020).

\section{Notes and references}

1 H. Uoyama, K. Goushi, K. Shizu, H. Nomura and C. Adachi, Nature, 2012, 492, 234-238.

2 S. Xu, R. Chen, C. Zheng and W. Huang, Adv. Mater., 2016, 28, 9920-9940.

3 Z. Yang, Z. Mao, Z. Xie, Y. Zhang, S. Liu, J. Zhao, J. Xu, Z. Chi and M. P. Aldred, Chem. Soc. Rev., 2017, 46, 915-1016.

4 R. Kabe and C. Adachi, Nature, 2017, 550, 384-387.

5 K. Y. Zhang, Q. Yu, H. Wei, S. Liu, Q. Zhao and W. Huang, Chem. Rev., 2018, 118, 1770-1839. 
6 A. Endo, M. Ogasawara, A. Takahashi, D. Yokoyama, Y. Kato and C. Adachi, Adv. Mater., 2009, 21, 4802-4806.

7 Q. Zhang, Q. Zhou, Y. Cheng, L. Wang, D. Ma, X. Jing and F. Wang, Adv. Funct. Mater., 2006, 16, 1203-1208.

8 Y. Liu, C. Li, Z. Ren, S. Yan and M. R. Bryce, Nat. Rev. Mater., 2018, 3, 18020.

9 Q. Zhang, B. Li, S. Huang, H. Nomura, H. Tanaka and C. Adachi, Nat. Photonics, 2014, 8, 326.

10 Y. Deng, D. Zhao, X. Chen, F. Wang, H. Song and D. Shen, Chem. Commun., 2013, 49, 5751-5753.

11 K. Jiang, L. Zhang, J. Lu, C. Xu, C. Cai and H. Lin, Angew. Chem., Int. Ed., 2016, 55, 7231-7235.

12 X. Dong, L. Wei, Y. Su, Z. Li, H. Geng, C. Yang and Y. Zhang, J. Mater. Chem. C, 2015, 3, 2798-2801.

13 K. Jiang, Y. Wang, C. Cai and H. Lin, Chem. Mater., 2017, 29, 4866-4873.

14 J. Liu, N. Wang, Y. Yu, Y. Yan, H. Zhang, J. Li and J. Yu, Sci. Adv., 2017, 3, e1603171.

15 Y. Mu, H. Shi, Y. Wang, H. Ding and J. Li, J. Mater. Chem. C, 2017, 5, 10894-10899.

16 Q. Li, M. Zhou, M. Yang, Q. Yang, Z. Zhang and J. Shi, Nat. Commun., 2018, 9, 734.

17 Q. Li, M. Zhou, Q. Yang, Q. Wu, J. Shi, A. Gong and M. Yang, Chem. Mater., 2016, 28, 8221-8227.

18 J. Tan, R. Zou, J. Zhang, W. Li, L. Zhang and D. Yue, Nanoscale, 2016, 8, 4742-4747.

19 Y. Chen, J. He, C. Hu, H. Zhang, B. Lei and Y. Liu, J. Mater. Chem. C, 2017, 5, 6243-6250.

20 J. Liu, H. Zhang, N. Wang, Y. Yu, Y. Cui, J. Li and J. Yu, ACS Mater. Lett., 2019, 1, 58-63.

21 Q. Wei, N. Fei, A. Islam, T. Lei, L. Hong, R. Peng, X. Fan, L. Chen, P. Gao and Z. Ge, Adv. Opt. Mater., 2018, 6, 1800512.

22 H. Tanaka, K. Shizu, H. Miyazaki and C. Adachi, Chem. Commun., 2012, 48, 11392-11394.

23 Y. Gong, L. Zhao, Q. Peng, D. Fan, W. Z. Yuan, Y. Zhang and B. Z. Tang, Chem. Sci., 2015, 6, 4438-4444.

24 B. Zhou and D. Yan, Adv. Funct. Mater., 2019, 29, 1807599.

25 B. Wang, Y. Mu, H. Zhang, H. Shi, G. Chen, Y. Yu, Z. Yang, J. Li and J. Yu, ACS Cent. Sci., 2019, 5, 349-356.
26 K. Jiang, S. Sun, L. Zhang, Y. Lu, A. Wu, C. Cai and H. Lin, Angew. Chem., Int. Ed., 2015, 54, 5360-5363.

27 Q. Zhang, J. Li, K. Shizu, S. Huang, S. Hirata, H. Miyazaki and C. Adachi, J. Am. Chem. Soc., 2012, 134, 14706-14709.

28 S. Wang, X. Yan, Z. Cheng, H. Zhang, Y. Liu and Y. Wang, Angew. Chem., Int. Ed., 2015, 54, 13068-13072.

29 Q. Zhang, H. Kuwabara, W. J. Potscavage, S. Huang, Y. Hatae, T. Shibata and C. Adachi, J. Am. Chem. Soc., 2014, 136, 18070-18081.

30 T. Hofbeck, U. Monkowius and H. Yersin, J. Am. Chem. Soc., 2015, 137, 399-404.

31 S. Hirata, Y. Sakai, K. Masui, H. Tanaka, S. Y. Lee, H. Nomura, N. Nakamura, M. Yasumatsu, H. Nakanotani, Q. Zhang, K. Shizu, H. Miyazaki and C. Adachi, Nat. Mater., 2015, 14, 330-336.

32 D. Zhang, L. Duan, Y. Zhang, M. Cai, D. Zhang and Y. Qiu, Light: Sci. Appl., 2015, 4, e232.

33 L. Bergmann, G. J. Hedley, T. Baumann, S. Bräse and I. D. W. Samuel, Sci. Adv., 2016, 2, e1500889.

34 R. Gao and D. Yan, Chem. Sci., 2017, 8, 590-599.

35 T. Ha, Methods, 2001, 25, 78-86.

36 P. Lutsyk, R. Arif, J. Hruby, A. Bukivskyi, O. Vinijchuk, M. Shandura, V. Yakubovskyi, Y. Kovtun, G. A. Rance, M. Fay, Y. Piryatinski, O. Kachkovsky, A. Verbitsky and A. Rozhin, Light: Sci. Appl., 2016, 5, e16028.

37 F. B. Dias, K. N. Bourdakos, V. Jankus, K. C. Moss, K. T. Kamtekar, V. Bhalla, J. Santos, M. R. Bryce and A. P. Monkman, Adv. Mater., 2013, 25, 3707-3714.

38 G. D. Scholes, G. R. Fleming, A. Olaya-Castro and R. van Grondelle, Nat. Chem., 2011, 3, 763.

39 C. Vijayakumar, V. K. Praveen, K. K. Kartha and A. Ajayaghosh, Phys. Chem. Chem. Phys., 2011, 13, 4942-4949.

40 P. Parkinson, C. E. I. Knappke, N. Kamonsutthipaijit, K. Sirithip, J. D. Matichak, H. L. Anderson and L. M. Herz, J. Am. Chem. Soc., 2014, 136, 8217-8220.

41 T. Senden, R. J. A. van Dijk-Moes and A. Meijerink, Light: Sci. Appl., 2018, 7, 8.

42 P.-Z. Chen, Y.-X. Weng, L.-Y. Niu, Y.-Z. Chen, L.-Z. Wu, C.-H. Tung and Q.-Z. Yang, Angew. Chem., Int. Ed., 2016, 55, 2759-2763. 